\title{
Biochemical Studies on Energy Metabolism in the Conduction System of Bovine Heart
}

\author{
Naohiko Tsuyuguchi, M.D.*, Koji Matsumura, M.D.*, \\ Yoshiyuki Tamura, M.D.*, Toshiharu Niki, M.D.*, \\ Hiroyoshi Mori, M.D.*, and Kenji AKI, M.D.**
}

\begin{abstract}
Summary
The conduction system of bovine heart was studicd to clarify the characteristics of its energy metabolism. Results showed that its mitochondrial oxygen uptake was much lower than that of ordinary heart muscle with succinate as substrate but similar to that of ordinary heart muscle with glutamate + malate as substrate. The activity of succinate dehydrogenase was lower than that in ordinary heart muscle. The total activity of isozymes of lactate dehydrogenase was lower in the specialized heart muscle than in ordinary heart muscle. The main isozyme of lactate dehydrogenase in the specialized heart muscle was LDH $1\left(\mathrm{H}_{4}\right)$. The cytoplasmic $\mathrm{NAD}^{+} / \mathrm{NADH}$ ratio was much higher in the specialized heart muscle than in ordinary heart muscle. These results suggest that in the specialized heart muscle energy is mainly derived from aerobic metabolism.
\end{abstract}

\section{Additional Indexing Words:}

Mitochondrial oxygen uptake Succinate dehydrogenase Lactate dehydrogenase Isozyme of lactate dehydrogenase $\quad \mathrm{NAD}^{+} / \mathrm{NADH}$ ratio Ordinary heart muscle Specialized heart muscle

7 HE cardiac conduction system has a central function in propagation of 1 impulses. This tissue is known to differ from ordinary heart muscle both morphologically and physiologically, and thus it is thought that it probably also differs from the latter metabolically. In fact, certain metabolic differences have been found. Histochemical studies have shown that its glycogen content is higher, ${ }^{1,2)}$ and its succinate dehydrogenase activity is much lower than those in ordinary heart muscle. ${ }^{37,4)}$ Moreover, oxygen uptake of slices of the specialized heart muscle is lower than that of slices of ordinary heart muscle. ${ }^{5,6)}$ Furthermore, the specialized heart muscle has

From the Second Department of Internal Medicine * and the Division of Enzyme Regulation, Institute for Enzyme Research, ** School of Medicine, Tokushima University, Kuramoto-cho, Tokushima-city 770, Japan.

Address for reprint: Yoshiyuki Tamura, M.D., Second Department of Internal Medicine, School of Medicine, Tokushima University, Kuramoto-cho, Tokushima-city 770, Japan.

Received for publication December 19, 1979. 
a greater capacity to survive anoxia. ${ }^{7}$ These findings suggested that in the specialized heart muscle energy might be mainly supplied by anaerobic metabolism.

In this study we compared the characteristics of energy metabolism in the cardiac conduction system and in ordinary heart muscle. For this purpose, we examined energy generation in these tissues by measuring mitochondrial respiration, the activity of succinate dehydrogenase, the activity and isozyme pattern of lactate dehydrogenase, and the cytoplasmic $\mathrm{NAD}^{+1}$ $\mathrm{NADH}$ ratio.

\section{Materials and Methods}

In ungulates, the cardiac conduction system can easily be separated from the surrounding myocardium, ${ }^{8)}$ and in this study we used bovine heart for experiments, because its conduction system was large and discrete. The heart was rapidly removed at the slaughterhouse and brought to the laboratory on ice, and the conduction system was dissected out as soon as possible in a cold room. Fig. 1 is a photograph of the conduction system of a bovine heart; it is composed from an atrioventricular node, a bundle of His, and right and left bundle branches. Ordinary heart muscle was obtained from the left ventricular wall.

Mitochondria were prepared as described by Chance and Hagihara. ${ }^{9)}$ Specialized or ordinary heart muscle was finely minced in cold isolation medium (0.21 M mannitol-0.07 M sucrose, $0.2 \mathrm{mM}$ EDTA, adjusted to $\mathrm{pH} 7.4$ with Tris base at $4^{\circ} \mathrm{C}$ ), and incubated with Nagarse (crystalline bacterial alkaline proteinase) for $20 \mathrm{~min}$ at $4^{\circ} \mathrm{C}$. The resulting suspension was diluted 2 -fold and homogenized

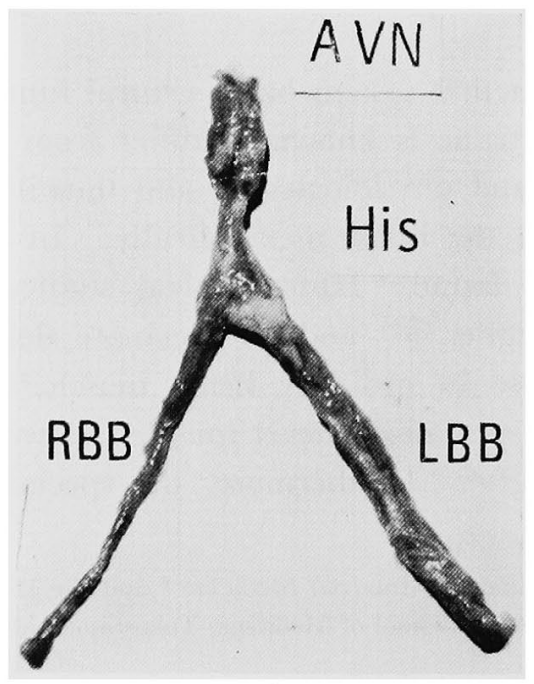

Fig. 1. Specialized heart muscle from bovine heart. The specialized heart muscle is composed of an atrioventricular node (AVN), bundle of His (His), and right and left bundle branches (RBB and $\mathrm{LBB}$ ). 
in a glass teflon homogenizer. The homogenate was centrifuged for $5 \mathrm{~min}$ at $500 \mathrm{~g}$ and the supernatant obtained was centrifuged for $20 \mathrm{~min}$ at $12,000 \mathrm{~g}$ in a refrigerated centrifuge. The precipitate was suspended in the isolation medium and promptly used for analysis of mitochondrial respiration. Mitochondrial respiration was measured polarographically in reaction medium containing $10 \mathrm{mM}$ phosphate buffer ( $\mathrm{pH} 7.4$ ), $0.3 \mathrm{M}$ mannitol, $0.01 \mathrm{M} \mathrm{KCl}$, and $0.25 \mathrm{mM}$ EDTA. Succinate or glutamate + malate was used as substrate. The following indicators of mitochondrial respiration were determined by the procedure of Chance and Williams ${ }^{\mathbf{1 0})}$ : mitochondrial oxygen uptake (natoms oxygen uptake/mg protein $/ \mathrm{min}$ ) and the $\mathrm{P} / \mathrm{O}$ ratio ( $\mathrm{n}$ mole ATP produced/n atom oxygen consumed).

Succinate dehydrogenase (SDH) activity was measured with a 2 wavelength spectrophotometer (Hitachi 356) at $550-600 \mathrm{~nm}$ in the following assay medium ${ }^{11)}$ : $60 \mathrm{mM}$ phosphate buffer $(\mathrm{pH}$ 7.6), $1 \mathrm{mM} \mathrm{KCN}, 72 \mu \mathrm{M} \mathrm{2,6-dichlorindophenol}$ (DCIP), $0.1 \mathrm{mM}$ phenazine methosulphate (PMS), $0.75 \mathrm{mM} \mathrm{CaCl} \mathrm{C}_{2}, 10 \mu \mathrm{M}$ phospholipase $\mathrm{C}$, and $20 \mathrm{mM}$ succinate. Enzyme activity was expressed as nmoles DGIP reduced $/ \mathrm{mg}$ protein $/ \mathrm{min}$.

Lactate dehydrogenase ( $\mathrm{LDH})$ activity was measured spectrophotometrically at $340 \mathrm{~nm}$ in $0.1 \mathrm{M}$ phosphate buffer $(\mathrm{pH} 7.4), 0.1 \mathrm{mM} \mathrm{NADH}$ and $1 \mathrm{mM} \mathrm{Na}$ pyruvate. ${ }^{12)}$ Enzyme activity was expressed as moles $\mathrm{NADH}$ oxidized/mg protein/min. Disc gel electrophoresis was performed to resolve the isozymes of LDH. After electrophoresis, $\mathrm{LDH}$ activity on the gel was located by incubating the gel in $20 \mathrm{ml}$ of $0.1 \mathrm{M}$ phosphate buffer ( $\mathrm{pH} \mathrm{7.4)} \mathrm{containing} 2.3 \mathrm{Gm}$ of NAD and $2 \mathrm{mg}$ of PMS. The densitogram was recorded with a dual-wavelength TLS scanner (Schimazu CS-900).

The redox state of the cytoplasm was calculated from the following equation: $\mathrm{NAD}^{+} / \mathrm{N} \Lambda \mathrm{DH}=$ pyruvate/lactate $\times 1 / \mathrm{K}\left(\mathrm{K}=1.11 \times 10^{-4}\right) \cdot{ }^{13} \quad$ Lactate and pyruvate contents were measured at $460 \mathrm{~nm}$ with a fluorescence spectrophotometer (Hitachi

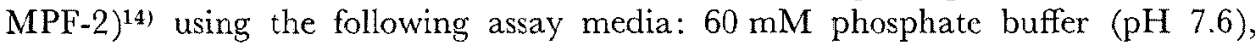
$0.1 \mathrm{mM} \mathrm{NADH}, 0.5 \mu \mathrm{g} \mathrm{LDH}$ for lactate assay. ${ }^{15)}$

The protein concentrations of mitochondrial and supernatant fractions were measured by the method of Lowry et $\mathrm{al}^{16)}$ with crystalline bovine serum albumin as a standard.

Results are expressed as mean \pm S.D. of the number of experiments indicated.

\section{Results}

Table I shows the values for various parameters of respiration of mitochondria isolated from specialized and ordinary heart muscles. The $\mathrm{P} / \mathrm{O}$ ratios of both types of muscle were nearly the theoretical values of 2.0 for succinate and 3.0 for glutamate + malate. These results also show that the preparations of mitochondria of both types of muscle were as active for oxidative phosphorylation. The oxygen uptakes (natoms oxygen uptake/mg protein $/ \mathrm{min}$ ) of mitochondria of specialized and ordinary heart muscles were 126.5 and 220.2, respectively, with succinate as substrate and 138.5 and 148.6, respectively, with glutamate+malate as substrate. Oxygen uptake of mitochondria of the specialized heart muscle was significantly lower than 
Table I. Parameters of Respiration of Mitochondria of Heart Muscles

\begin{tabular}{|c|c|c|c|}
\hline Heart Muscle & Substrate & $\mathrm{Qo}_{2}$ & $\mathrm{P} / \mathrm{O}$ \\
\hline Specialized $(n=9)$ & Succinate & $126.5 \pm 30.4$ & $1.8 \pm 0.2$ \\
\hline Ordinary $(n=20)$ & $"$ & $\begin{array}{c}220.2 \pm 32.8 \\
p<0.001\end{array}$ & $\begin{array}{l}2.2 \pm 0.2 \\
p<0.001\end{array}$ \\
\hline Specialized $(n=14)$ & Glutamate + Malate & $138.9 \pm 21.8$ & $2.8 \pm 0.2$ \\
\hline Ordinary $(n=23)$ & " & $\begin{array}{c}148.6 \pm 20.2 \\
\text { N.S. }\end{array}$ & $\begin{array}{c}2.9 \pm 0.2 \\
\text { N.S. }\end{array}$ \\
\hline
\end{tabular}

Values are means $\pm \mathrm{SD}$ for the number of experiments shown in parentheses. P values indicate significance of differences between values for the 2 heart muscles. N.S. $=$ not significant; $Q \mathrm{QO}_{2}=$ natoms oxygen uptake/mg protein/min.

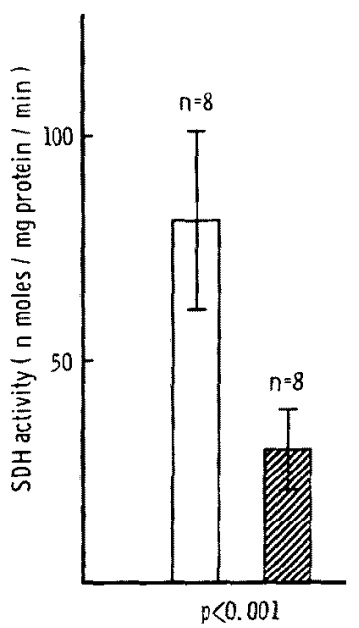

Fig. 2.

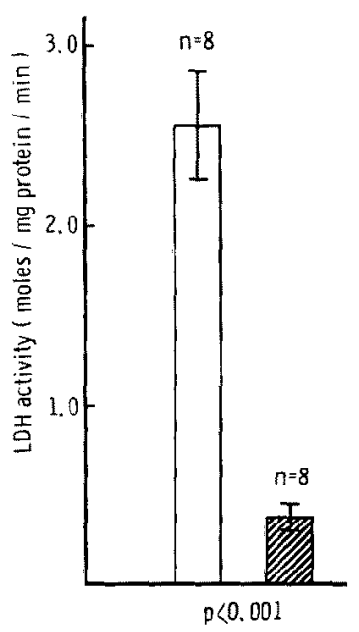

Fig. 3.

Fig. 2. (left). Succinate dehydrogenase activities of bovine heart. $\square$, ordinary heart muscle; $\square$, specialized heart muscle. The $P$ value shows the significance of the difference between the 2 activities.

Fig. 3 (right). Lactate dehydrogenase activities of bovine heart. $\square$, ordinary heart muscle; $\square$, specialized heart muscle. The $P$ value shows the significance of the difference between the 2 activities.

that of mitochondria of ordinary heart muscle with succinate as substrate, but not significantly different from the latter with glutamate + malate as substrate. Oxygen uptake by mitochondria of the specialized heart muscle was similar with succinate and glutamate + malate as substrates.

Since oxygen uptake by mitochondria of the specialized heart muscle was very low with succinate as substrate, we measured their succinate dehydrogenase activity. Fig. 2 shows that the $\mathrm{SDH}$ activity (nmoles DCIP reduced $/ \mathrm{mg}$ protein $/ \mathrm{min}$ ) of the specialized heart muscle (29.4) was significantly lower than that of ordinary heart muscle (81.5). 
LDH activity is an index of anaerobic metabolism. Fig. 3 shows that the LDH activity (moles NADH oxidized/mg protein/min) in specialized heart muscle (0.37) was significantly lower than that in ordinary heart muscle (2.55). Fig. 4 shows densitograms of the isozymes of LDH separated by electrophoresis. Specialized heart muscle gave 1 main band, ordinary heart muscle gave 2, and a mixture of the 2 heart muscles gave 2 major bands in the positions of those of the ordinary heart muscle. These results show that the main component in specialized heart muscle is $\mathbf{L D H ~} 1\left(\mathrm{H}_{4}\right)$, whereas the main components in ordinary heart muscle are LDH $1\left(\mathrm{H}_{4}\right)$ and LDH 2 $\left(\mathrm{H}_{3} \mathrm{M}_{1}\right)$.

As shown in Table II, the $\mathrm{NAD}^{+} / \mathrm{NADH}$ ratio in the cytoplasm was 1251 in specialized heart muscle and 77 in ordinary heart muscle. The

(a)

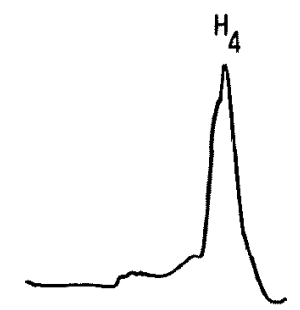

(b)

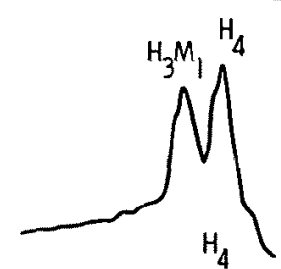

(c)

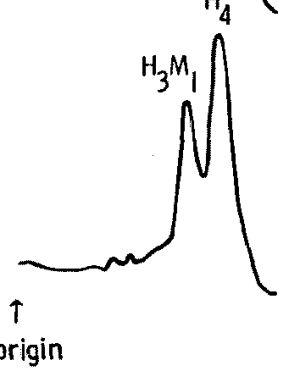

Fig. 4. Densitometric trace of LDH isozymes of bovine heart. (a), (b), and (c) are tracings of isozymes in specialized heart muscle, ordinary heart muscle, and a mixture of the 2 , respectively.

Table II. Cytoplasmic NAD + NADH Ratios of Heart Muscles

\begin{tabular}{c|c}
\hline Heart Muscle & NAD $^{+} / \mathrm{NADH}$ \\
\hline Specialized $(\mathrm{n}=15)$ & 1251 \\
Ordinary $(\mathrm{n}=15)$ & 77
\end{tabular}


higher $\mathrm{NAD}^{+} / \mathrm{NADH}$ ratio in the specialized heart muscle provides support for the idea that this muscle is an aerobic tissue.

\section{Discussion}

Mitochondria have a central role in generating ATP and are also important in energy metabolism. The mitochondria of specialized heart muscle have not previously been isolated. Therefore, we isolated them and investigated their respiration. Fig. 5 is a schematic representation of the electron transfer systems of specialized heart muscle and ordinary heart muscle. Since succinate dehydrogenase activity is low in specialized heart muscle, electron transfer from succinate to the respiratory chain is slower in specialized heart muscle than in ordinary heart muscle. On the other hand, since mitochondrial oxygen uptake is similar in the 2 types of heart muscle with glutamate+malate as substrate, the rates of electron transfer from NADH-dependent substrates to the respiratory chain seem to be similar in these muscles. Furthermore, the rates of electron transfer from succinate and from NADH-dependent substrates seem to be similar in specialized heart muscle.

Since the LDH reaction strongly favors lactate formation from pyruvate, the activity of LDH can be thought to express the width of the pathway of lactate formation. Histochemical studies have shown that the LDH activity of specialized heart muscle is low or the same as that of ordinary heart muscle.1),3) In isolated tissues LDH must be measured rapidly, because it is unstable. Our spectrophotometric measurements of LDH activity in freshly isolated preparations showed that formation of lactate was less in specialized

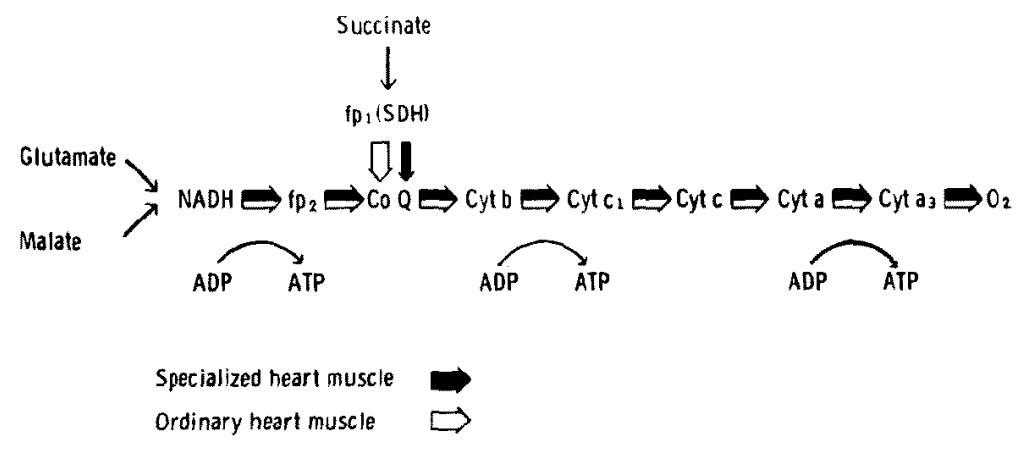

Fig. 5. Schematic representation of the elcctron transfor systems of mitochondria of specialized and ordinary heart muscles. The rate of electron transfer from NADH-dependent substrates to the respiratory chain was similar in specialized heart muscle and in ordinary heart muscle, but the rate of electron transfer from succinate to the respiratory chain was slower in specialized heart muscle than in ordinary heart muscle. 
heart muscle than in ordinary heart muscle. There are 5 isozymes of LDH, each composed of 4 subunits of 2 parent molecules, the H-type and M-type; the H-type is found in aerobic tissues, such as cardiac muscle, and M-type is found in the more anaerobic tissues, such as voluntary skeletal muscle. The cellular proportion of these subunits are changed by various factors: i.e., differentiation, hormonal responses, loss of the nerve supply, various diseases and change in oxygen tension. ${ }^{17), 18}$ ) A low oxygen tension favors synthesis of the H-type. ${ }^{191,20)}$ Thus the isozyme pattern of LDH reflects the metabolism of a given tissue. Our findings on the isozyme patterns of $\mathrm{LDH}$ indicate that the specialized heart muscle is an aerobic tissue.

The factor controlling the direction of the $\mathrm{LDH}$ reaction is the $\mathrm{NAD}^{+} /$ $\mathrm{NADH}$ ratio. We found that the cytoplasmic $\mathrm{NAD}^{+} / \mathrm{NADH}$ ratio was high in specialized heart muscle. In other words, the redox state of the cytoplasm of the specialized heart muscle may be higher than that of ordinary heart muscle. Therefore, the $\mathrm{LDH}$ reaction should favor pyruvate formation from lactate more in specialized heart muscle than in ordinary heart muscle.

It has been considered that in specialized heart muscle energy is supplied mainly by anaerobic metabolism from the following reasons: (i) Oxygen uptake by slices of the conduction tissue is low. ${ }^{51,6)}$ (ii) Succinate dehydrogenase activity is low in specialized heart muscle..31,4) (iii) The glycogen content of the specialized heart muscle is high.1,2) (iv) Specialized heart muscle can survive anoxia.7 However, we found that oxygen uptake by mitochondria of the specialized heart muscle was almost the same to that of mitochondria of ordinary heart muscle with NADH-dependent substrates. Moreover, although the succinate dehydrogenase activity of mitochondria from specialized heart muscle was low, their oxygen uptakes with succinate and with glutamate + malate were almost the same. These findings eliminate reasons (i) and (ii) for concluding that specialized heart muscle depends mainly on anaerobic metabolism. It is well known that increase in glycolysis is an important compensatory mechanism in myocardial ischemia. ${ }^{21)}$ Myocardial glycogen can be broken down during enhanced glycolysis and anaerobic ATP generation to meet the needs of the tissue in anoxia. ${ }^{22}$ The high glycogen content of specialized heart muscle may similarly make specialized heart muscle more resistant to anoxia. Therefore, reasons (iii) and (iv) do not prove that the specialized heart muscle gets its energy mainly from anaerobic metabolism in aerobic state. On the contrary we conclude from our results on mitochondrial respiration, $\mathrm{LDH}$ activity, the $\mathrm{LDH}$ isozyme pattern and the cytoplasmic $\mathrm{NAD}^{+} / \mathrm{NADH}$ ratio that the specialized heart muscle is mainly supplied with energy from aerobic metabolism rather than anaerobic metabolism. 


\section{REFERENCES}

1. Otsuka N, Hara T, Okamoto H: Histotopochemische Untersuchungen am Reizleitungssystem des Hundehcrzens. Histochemie 10:66, 1967

2. Yamazaki $\mathrm{K}$ : Biochemical studies on the auriculoventricular junctional system of heart. 1 . The glycogen content. J Biochem 10: 481,1929

3. Isaacson R, Boucek RJ: The atrioventricular conduction tissue of the dog. Histochemical properties; influence of electric shock. Am Heart J 75: 206, 1968

4. Kiritschenko WI, Egelkraut R: Eine histochemische Analyse der Stoffwechselsituation in den Sinus und Atrioventricularknoten des Herzens einiger Saugetiere. Acta Histochem 35: 75,1970

5. Murray JB: Oxygen uptake of atrioventricular conduction tissue of beef heart. Am J Physiol 177: 463, 1954

6. Schiebler TH, Stark M, Caeser R: Die Stoffwechselsituation des Reizleitungssystems. Klin Wschr 34: 181, 1956

7. Yamazaki $\mathrm{K}$ : Biochemical studies on the auriculoventricular junctional system of heart, 4. Studies on anaerobic oxidation of the auriculoventricular junctional system. J Biochem 12: 241,1936

8. Thornell LE: Morphological characteristics of Purkinje fibre bundles separated from their connective tissue sheath. J Mol Cell Cardiol 7: 191, 1975

9. Chance B, Hagihara B: Proc 5th Int Cong Biochem (Moscow) Symposium, vol 5, Pergamon Press, Oxford, p 3, 1963

10. Chance B, Williams GR: Respiratory enzyme in oxidative phosphorylation. J Biol Chem 217: 383, 1955

11. Gutman M, Edna BK, Singer TP: Multiple control mechanisms for succinate dehydrogenase in mitochondria. Biochem Biophys Res Commun 44: 526, 1971

12. Wroblewski F, Ladue JS: Lactic dehydrogenase activity in blood. Proc Soc Exp Biol Med 90: 210,1955

13. Williamson DH, Lund P, Krebs HA: The state of free nicotinamideadenine dinucleotide in cytoplasm and mitochondria of rat liver. Biochem J 103: 514, 1967

14. Czok R, Lamprecht W: Pyruvate, phosphopyruvate and D-glycerate-2-phosphate. in Methods of Enzymatic Analysis, ed by Bergmeyer HU, Academic Press, New York, p 14461448,1974

15. Gawehn K, Bergmeyer HU: D- $(-)$-lactate. in Methods of Enzymatic Analysis, ed by Bergmeyer HU, Academic Press, New York, p 1492-1495, 1974

16. Lowry GH, Rosenbrough NJ, Farr AL, Randall RJ: Protein measurement with the Folin phenol reagent. J Biol Chem 193: 265, 1951

17. Dawson DM, Goodfriend TL, Kaplan NO: Lactic dehydrogenases. Functions of the two types. Rates of synthesis of the two major forms can be correlated with metabolic differentiation. Science 143; 929, 1964

18. Kaplan NO: Effect of hormones and environmental factors on lactic dehydrogenase. J Cell Com Physiol 66: 1, 1965

19. Mager M, Blatt WF, Natale PJ, Blatteis CM: Effect of high altitude on lactic dehydrogenase isozymes of neonatal and adult rats. Am J Physiol 215: 8, 1968

20. Penny DG: Lactate dehydrogenase subunit and activity changes in hypertrophied heart of hypoxically exposed rat. Biochim Biophys Acta 358: 21, 1974

21. Brachfeld N, Scheuer J: Metabolism of glucose by the ischemic dog heart. Am J Physiol 212: 603,1967

22. Scheuer J, Stezoski SW: Protective role of increased myocardial glycogen stores in cardiac anoxia in the rat. Circulat Res 27:835, 1970 